\title{
Microwave Heating in Organic Synthesis and Drug Discovery
}

\author{
Hong Liu and Lei Zhang \\ State Key Laboratory of Drug Research, Shanghai Institute of Materia Medica, \\ Chinese Academy of Sciences
}

China

\section{Introduction}

Microwave dielectric heating was firstly reported on the use in organic chemistry by Gedye (Gedye, R. et al., 1986) and Giguere/Majetich (Giguere, R. J. et al., 1986) in the mid-1980s. However, it takes a long time before the wide application of this technology in the late 1980s and early 1990s. This has been principally attributed to the lack of controllability and reproducibility of the initial domestic microwave ovens implemented in organic chemistry, and partly due to a general lack of understanding of the basics of microwave dielectric heating. Since the year 2000, dedicated commercial microwave reactors for chemical synthesis have become available, promoting the wide spread of microwave energy in academic and industry to heat various chemical transformations. Nowadays, this enabling technology has been considerably exploited in organic synthesis and drug discovery.

Microwave technology triggers heating into the reacting system by either dipolar polarization or ionic conduction. When irradiated at microwave frequencies, electromagnetic waves pass through the dipoles or ions of the sample and cause the molecules to oscillate. In this process, energy is lost in the form of heat through molecular friction and dielectric loss. Because microwave radiation is introduced into the reaction system remotely without direct physical contact with reaction materials, this can lead to a rapid temperature increase throughout the sample causing less by-products or decomposition products. In contrast, conventional heating of organic reactions such as oil baths, sand baths or heating mantles are rather slow and create an inward temperature gradient, which may result in localized overheating and reagent decomposition when heated for prolonged periods.

The most prominent advantage of controlled microwave dielectric heating for chemical synthesis is the dramatic reduction in reaction time from days and hours to minutes. Moreover, microwave heating is able to reduce side reactions, increase yields, improve reproducibility, allow control of temperature and pressure, and even realize impossible reactions by conventional heating.

Since a large number of articles have been published in the area of microwave synthesis, including a number of general and specific review articles (Caddick, S. \& Fitzmaurice, R., 2009; Mavandadi, F. \& Lidström, P., 2004; Mavandadi, F. \& Pilotti, ̊̊., 2006; Kappe, C. O., 2004, 2008; Kappe, C. O. \& Dallinger, D., 2006; Wathey, B. et al., 2002) and several books (Hayes, B. L., 2002; Kappe, C. O. et al., 2009; Kappe, C. O. \& Stadler, A., 2005; Leadbeater, N. 
E., 2010; Loupy, A., 2006; Polshettiwar, V., 2010; Tierney, J. P. \& Lidström, P., 2005), in this chapter we only exemplify recent publications that demonstrate the impact of microwave heating on organic synthesis and drug discovery.

\section{Microwave in general synthetic transformations}

In early days, microwave heating was often used as an optional protocol when a particular reaction has failed to proceed under other conditions or requires exceedingly long reaction time or high temperature. Dedicated microwave chemistries have now made it obvious that many types of chemical transformations that require heating can be carried out successfully under microwave conditions. Microwave technology has also been applied in various formats ranging from the traditional solution-phase synthesis to solid-phase and solventfree reactions.

\subsection{Transition-metal-catalyzed reactions}

Transition metal-catalyzed reactions are of enormous significance to form carbon-carbon (C$\mathrm{C})$ and carbon-heteroatom $(\mathrm{C}-\mathrm{X})$ bonds in organic chemistry. These reactions typically need hours or days to reach completion under traditional reflux conditions and often require an inert atmosphere. Microwave heating has been demonstrated over the past few years to significantly expedite these transformations, in most cases without an inert atmosphere. Furthermore, the inverted temperature gradients under microwave conditions may lead to an increased lifetime of the catalyst by elimination of wall effects (Kappe, C. O., 2004).

\subsubsection{Suzuki reactions}

The Suzuki reaction, cross-coupling of aryl- or vinyl-boronic acid with an aryl- or vinylhalide catalyzed by a palladium complex, is one of the most versatile reactions for the construction of carbon-carbon bonds, in particular for the formation of biaryls. Recent developments have expanded the possible applications of this reaction enormously. Microwave-assisted Suzuki reactions can now be performed in many different ways and have been incorporated into a variety of challenging synthesis.

Under microwave-heated condition, the Suzuki coupling of aryl chlorides with boronic acids was performed in an aqueous media using the air- and moisture-stable palladium catalyst (Scheme 1). The protocol developed in this publication allowed a drastic reduction of the reaction time to $15 \mathrm{~min}$ and the products were obtained in good yields (Miao, G. et al., 2005).
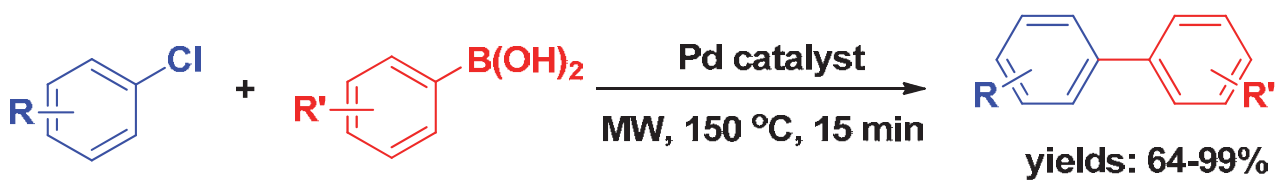

Scheme 1. Microwave-promoted Suzuki reactions of aryl chlorides.

Microwave activation enables a Suzuki coupling of boronic acids with aryl halides under solvent-free conditions using palladium catalyst system (Scheme 2). A large variety of boronic acids and bromo-, chloro- and iodoaryls could rapidly give biaryls in 10 minutes (Nun, P. et al., 2009). 


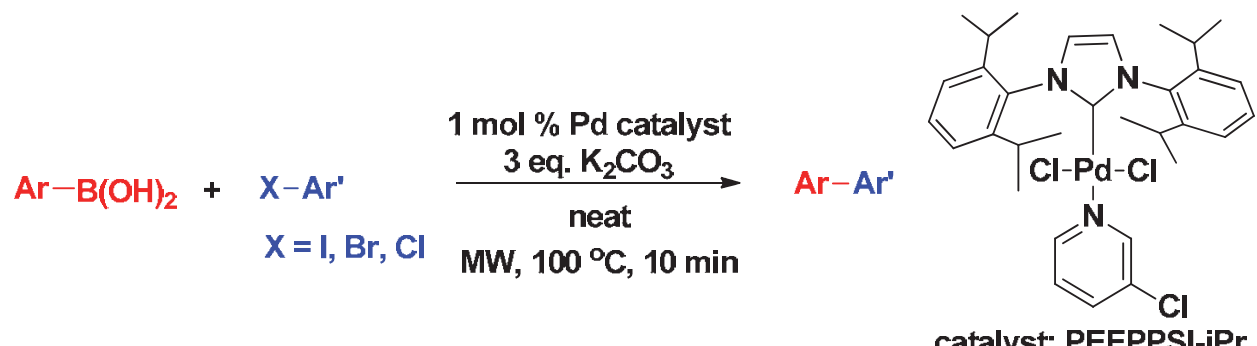

Scheme 2. Microwave-assisted solvent-free Suzuki reaction.

Replacement of the traditionally used Pd with less expensive Ni-based catalyst systems can significantly reduce costs for cross-couplings of this type especially when performed on scale. Kappe et al. reported a rapid and highly efficient microwave-assisted Ni-catalyzed Suzuki cross-coupling of aryl carbamates and sulfamates with boronic acid (Scheme 3). This protocol features coupling time of only $10 \mathrm{~min}$. Also, the microwave conditions work exceedingly well with aryl chlorides as electrophilic cross-coupling partners and the scalability of the coupling process is demonstrated up to $700 \mathrm{~mL}$ scale with a multimode microwave reactor (Baghbanzadeh, M. et al., 2011).

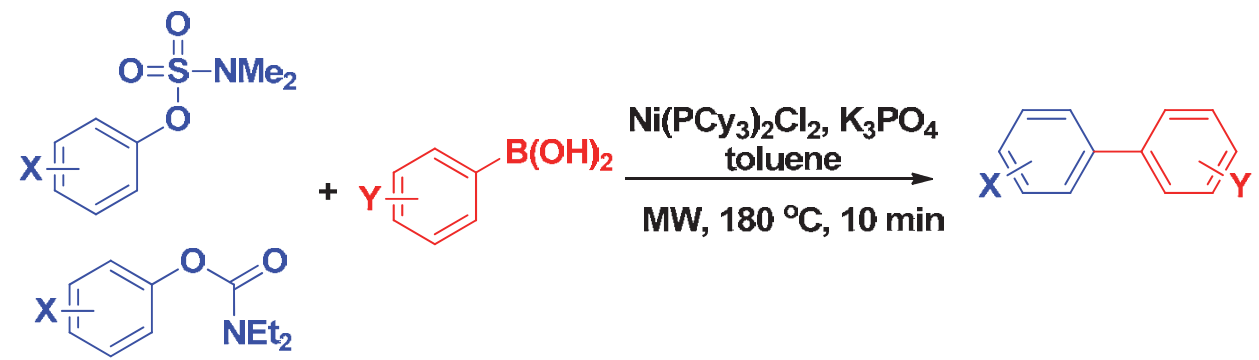

Scheme 3. Rapid nickel-catalyzed Suzuki reaction utilizing microwave heating.

We have successfully synthesized bromoenone of the Ni(II) complexes of $\beta$-alanine Schiff's base and developed a practical and highly efficient route to $a$-aryl and $a$-heteroarylsubstituted $\beta$-amino acids using the Suzuki coupling reaction (Scheme 4). The heterogeneous solution was stirred at $70{ }^{\circ} \mathrm{C}$ for $40 \mathrm{~min}$ under microwave irradiation. A broad range of aryl and heteroaryl substituents can be employed under the operationally simple and effective conditions (Ding, X. et al., 2009).

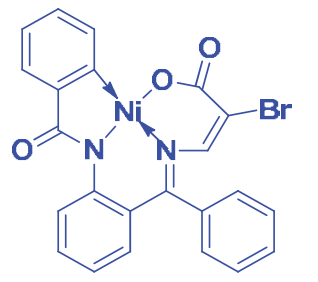

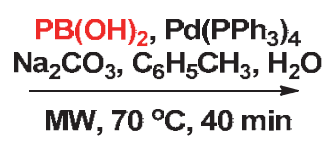<smiles>[R]C1=CN2C(=O)O[N+]23c2ccccc2C(=O)N3c2ccccc2C(c2ccccc2)=C1</smiles><smiles>[R]C(CN)C(=O)O</smiles>

Scheme 4. Microwave-assisted Suzuki couplings of Ni(II) complex with boric acids. 


\subsubsection{Heck reactions}

Heck reactions between aryl halides and alkenes are also well established under microwave conditions. Regioselectivity is a key issue in the Heck reaction. Larhed described a regioselective Heck coupling employing different arylboronic acids with both electron-rich and electron-poor olefins (Scheme 5). Controlled microwave processing was used to reduce reaction time from hours to minutes both in small scale and in $50 \mathrm{mmol}$ scale batch processes (Lindh, J. et al., 2007).

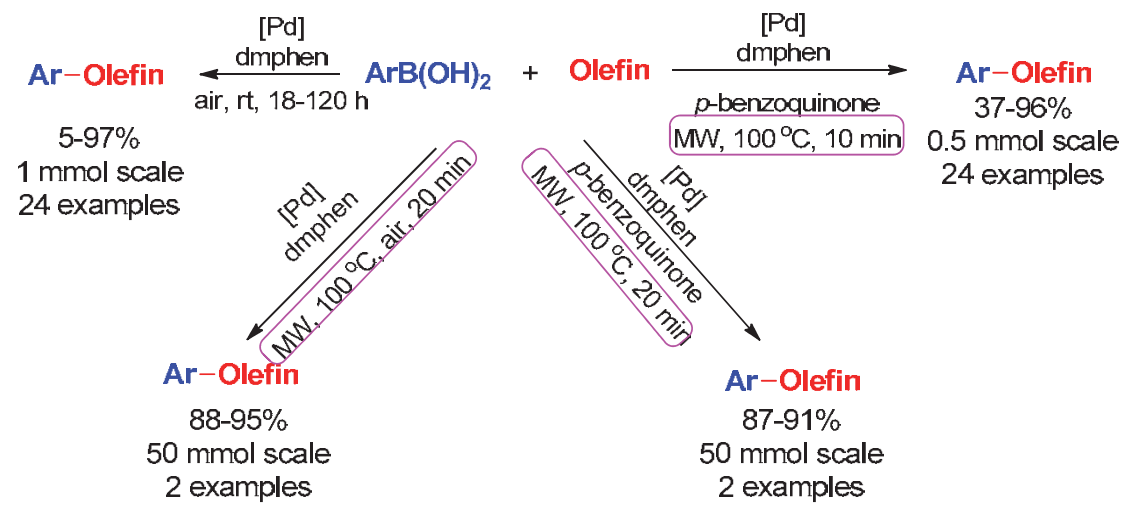

Scheme 5. Oxidative Heck reactions at room temperature and with microwave heating.

Another key issue in the microwave enhanced Heck reaction is asymmetric induction. Recently, a highly modular library of readily available phosphite-oxazoline ligands has been applied in the Pd-catalyzed asymmetric Heck reactions of several substrates and triflates under thermal and microwave conditions (Scheme 6). Both enantiomers of the Heck coupling products were obtained in excellent activities (conversion: $>100 \%$ in $10 \mathrm{~min}$ ), regioselectivities (>99\%) and enantioselectivities (>99\% ee) (Mazuela, J. et al., 2010).

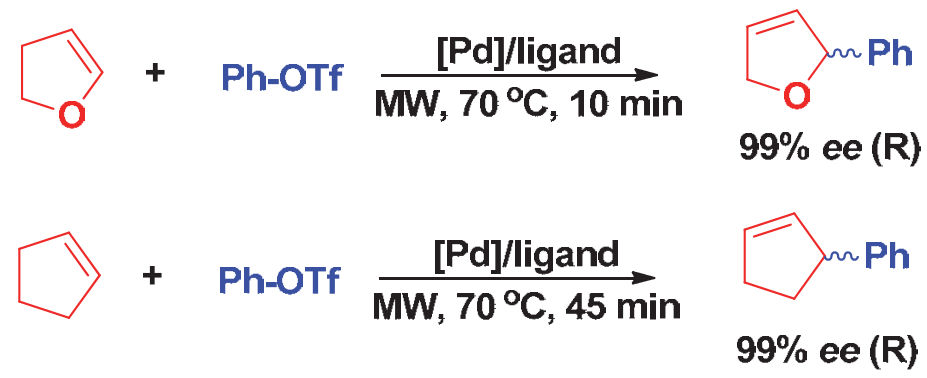

Scheme 6. Enantioselective Heck reactions under microwave-irradiation.

\subsubsection{Buchwald-Hartwig cross coupling reactions}

Buchwald-Hartwig chemistry, cross coupling of aryl halides or pseudohalides with primary or secondary amines, has become a powerful method for synthesizing arylamines. Conventionally, this reaction requires high temperature and long reaction time. Many fast and highly efficient applications have been developed in conjunction with microwave irradiation. 
We have developed a practical, convenient strategy for the preparation of arylamines (Scheme 7). The process was efficiently promoted by readily available $\mathrm{Cu}(\mathrm{OAc})_{2}$ in the presence of $\mathrm{DBU}$ under microwave irradiation. Both aromatic and aliphatic amines can be quickly coupled with various substituted aryl halides in good to excellent yields (Huang, H. et al., 2008a).

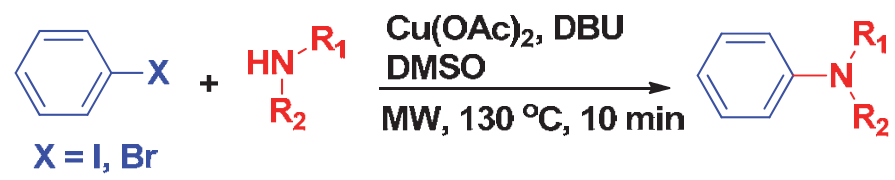

Scheme 7. Microwave-assisted cross-coupling of aryl halides with various nitrogen derivatives.

\subsubsection{Sonogashira coupling reactions}

The Sonogashira reaction, cross-coupling of aryl or vinyl halides with terminal alkynes, is an important example of metal-catalyzed carbon-carbon bond-forming reactions. This reaction has also been subjected to microwave enhancement. Some weaknesses of the original procedure are long reaction time (hours to days), limited choice of aryl halides, and complicated workup procedures. We developed an efficient and effective microwave-assisted cross-coupling of terminal alkynes with various aryl chlorides including sterically hindered, electron-rich, electron-neutral, and electron-deficient aryl chloride (Scheme 8). It proceeded faster and generally gave good-to-excellent yields. This simple catalytic system was also effective for Suzuki coupling, Buchwald-Hartwig amination, and Heck coupling reactions with unactivated aryl chlorides. A broad spectrum of substrates coupled effectively under microwave irradiation to provide the desired products in minutes (Huang, H. et al., 2008b).

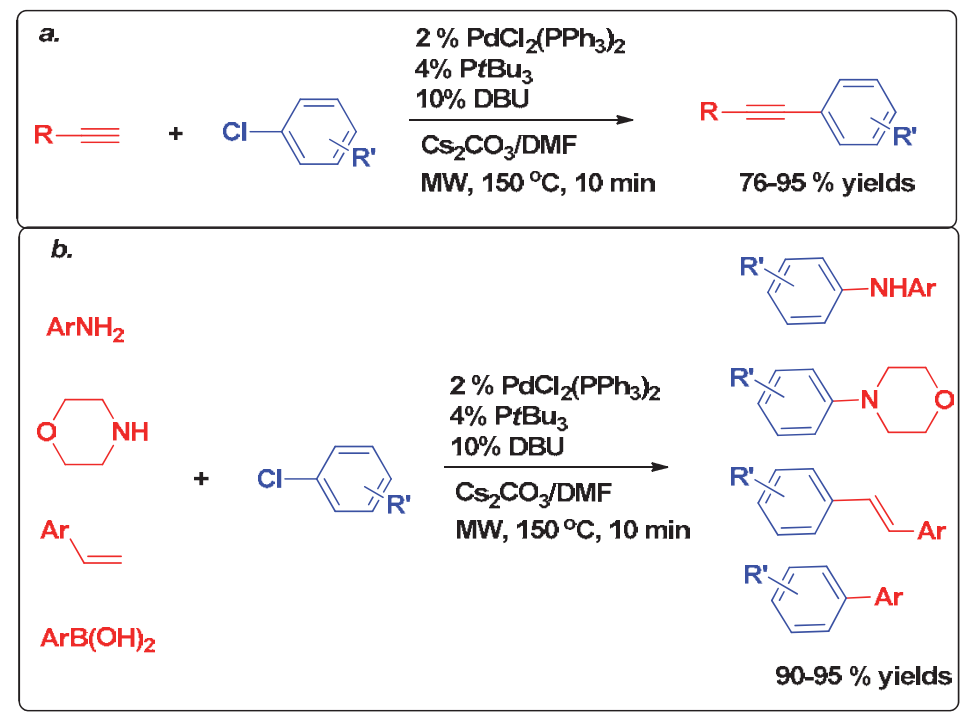

Scheme 8. a) Microwave-assisted Sonogashira coupling of aryl chlorides with alkynes. b) Microwave-assisted $\mathrm{C}-\mathrm{C}$ and $\mathrm{C}-\mathrm{N}$ bond-forming reactions with aryl chlorides. 


\subsubsection{Other $\mathrm{C}-\mathrm{X}$ bond forming reactions}

Enhanced by microwave, an efficient coupling protocol of arylboronic acids with amines proceeded rapidly and conveniently to afford $\mathrm{N}$-arylated amines in the presence of inexpensive $\mathrm{Cu}(\mathrm{OAc})_{2}$ and $\mathrm{DBU}$ (Scheme 9). Compared with the former Ullmann reaction conditions, this methodology developed a much faster way to construct $\mathrm{C}-\mathrm{N}$ bonds under microwave irradiation without using expensive ligand and palladium. A variety of substrates could participate in the process with higher purities and yields in short time (Chen, S. et al., 2008).

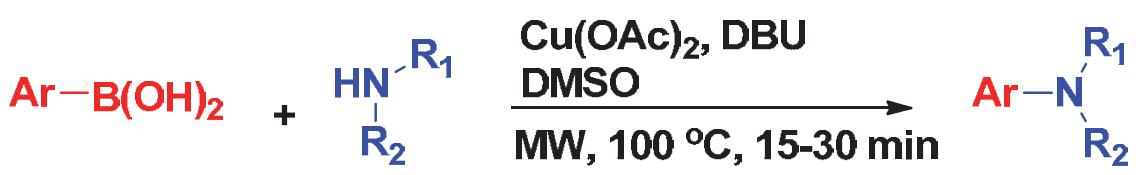

Scheme 9. Microwave-assisted $N$-arylation of amines with arylboronic acids.

An expeditious and efficient method was developed to prepare 2,6,9-substituted purines in higher purity and yields under microwave heating (Scheme 10). First, 2-chloro-6, 9substituted purines were prepared via a one-pot two-step reaction, which involves a sequential $S_{N} A r$ displacement of the $\mathrm{C} 6$ chloro substituent with various anilines and amines, followed by $\mathrm{N}$-alkylation and $\mathrm{N}$-arylation at the $\mathrm{N} 9$ position with different organic halides and boronic acids. Second, $\mathrm{NaBF}_{4}$ catalysis supports a $\mathrm{S}_{\mathrm{N}} \mathrm{Ar}$ substition of the $\mathrm{C} 2$ chloro displacement with high product conversion. All these reactions were carried out under microwave irradiation (Huang, H. et al., 2007). This protocol was applied in the preparation of novel purine derivatives with potent and selective inhibitory activity against c-Src tyrosine kinase (Huang, H. et al., 2010).<smiles>Clc1nc(Cl)c2nc[nH]c2n1</smiles>

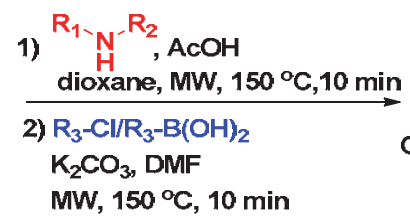<smiles>[R]N([R])c1nc(Cl)nc2c1ncn2[R3]</smiles>

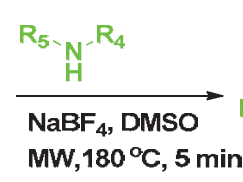<smiles>[R6]N([Y9])c1nc(N([R])[R])c2ncn([R3])c2n1</smiles>

Scheme 10. Microwave-assisted rapid synthesis of 2,6,9-substituted purines.

\subsection{Microwave-assisted multi-component reactions}

Multi-component reactions (MCRs) hold considerable utility in diversity generating of functional molecule libraries. Microwave-assisted organic synthesis accelerates a variety of synthetic transformations with prominent advantages of short reaction time and high yields. Thus, combing rapid microwave enhancement with diversifying MCRs can minimize reaction time, the number of steps, energy consumption, and maximize synthetic efficiency. Many different microwave-assisted MCRs has received considerable exploration, including Mannich, Ugi, Biginelli and other heterocycle-forming reactions.

\subsubsection{Microwave-assisted Mannich reactions}

Mannich reactions are of great importance to synthesize $\beta$-amino ketones traditionally via three-component condensation of a substituted methyl ketone, an aldehyde, and an amine. 
Bolm reported a proline-catalyzed direct asymmetric Mannich reaction under microwave irradiation (Scheme 11). After a short period of time, the Mannich products were obtained with only $0.5 \mathrm{~mol} \%$ of catalyst and up to $98 \%$ ee. (Rodríguez B. \& Bolm, C., 2006).

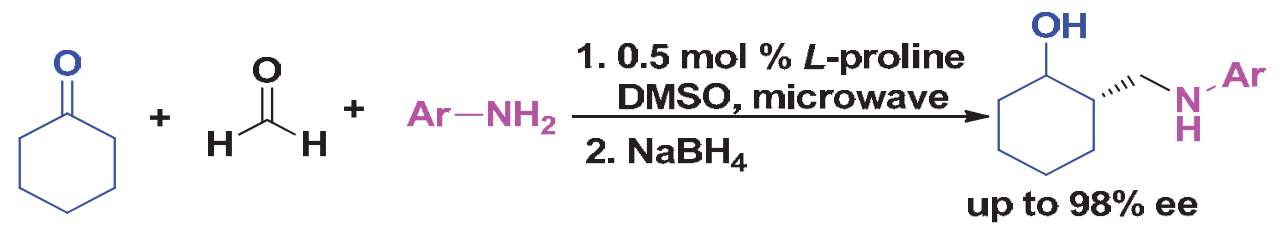

Scheme 11. Microwave-assisted asymmetric Mannich reaction.

Hao et al. described a mild microwave-assisted stereoselective Mannich reaction of aromatic aldehydes with 1,2-diphenylethanone and hetero-arylamines in water (Scheme 12). As opposed to conventional heating, this method proceeded faster and in higher yields under controlled microwave heating (Hao, W. et al., 2009).

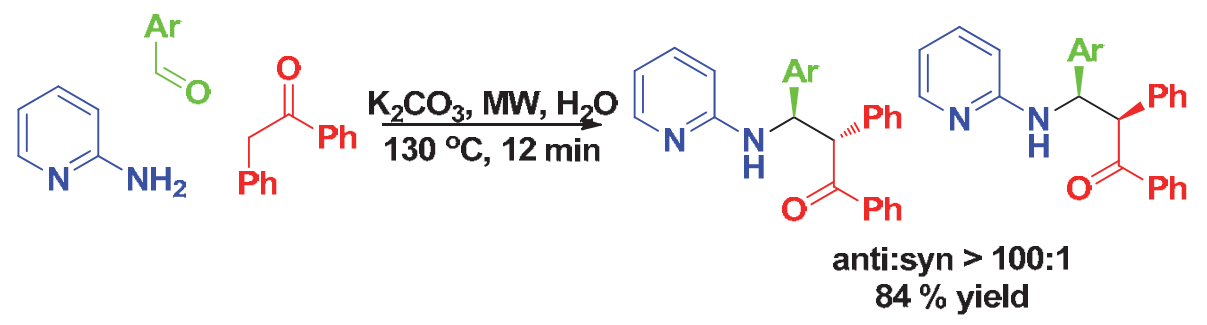

Scheme 12. Microwave-assisted Mannich reaction in water.

\subsubsection{Microwave-assisted Ugi reactions}

The Ugi reaction is widely used in the pharmaceutical industry for preparing libraries of compounds. Classically, the reaction is performed at room temperature in methanol with reaction time up to 48 hours. Recently, a rapid solvent-free microwave synthesis of five- and six-membered lactams via a three-component Ugi reaction was developed (Scheme 13). The reaction was carried out in much shorter time $\left(100{ }^{\circ} \mathrm{C}\right.$ for $\left.3 \mathrm{~min}\right)$ and the yields were improved in contrast to classical conditions (Jida, M. et al., 2010).

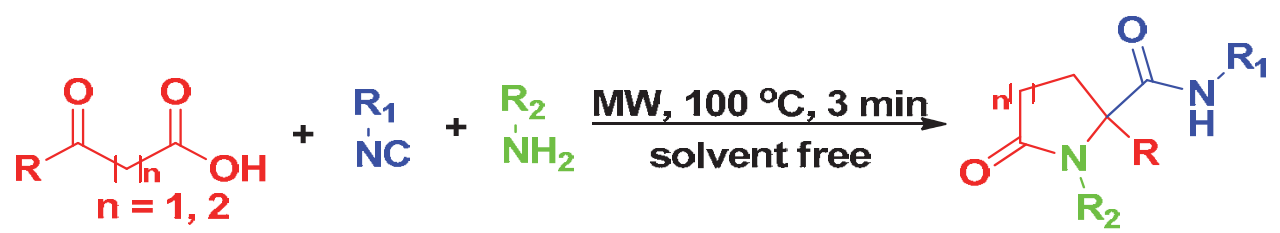

Scheme 13. Microwave-assisted solvent-free Ugi reaction.

\subsubsection{Microwave-assisted Biginelli reactions}

The Biginelli reaction is of great importance to the synthesis of biologically active dihydropyrimidines. It involves the acid-catalyzed condensation of aldehydes, $\mathrm{CH}$-acidic 
carbonyl components and urea-type building blocks. Kappe's group has made great contributions in the area of microwave-assisted Biginelli reactions. They have elaborately combined microwave irradiation with click chemistry (Khanetskyy, B. et al, 2004), parallel library-generation (Pisani, L. et al., 2007), solution- and solid-phase combinatorial chemistry based on this Biginelli reaction.

In an elegant example, Kappe et al. developed an efficient five-step linear protocol which involved an initial Biginelli multicomponent reaction for the generation of a variety of 2substituted pyrimidines in high yields and comparatively short reaction time (Scheme 14). All five synthetic steps required for the synthesis of the target structures were carried out under microwave irradiation, both in solution phase and on solid phase (Matloobi, M. \& Kappe, C. O., 2007).

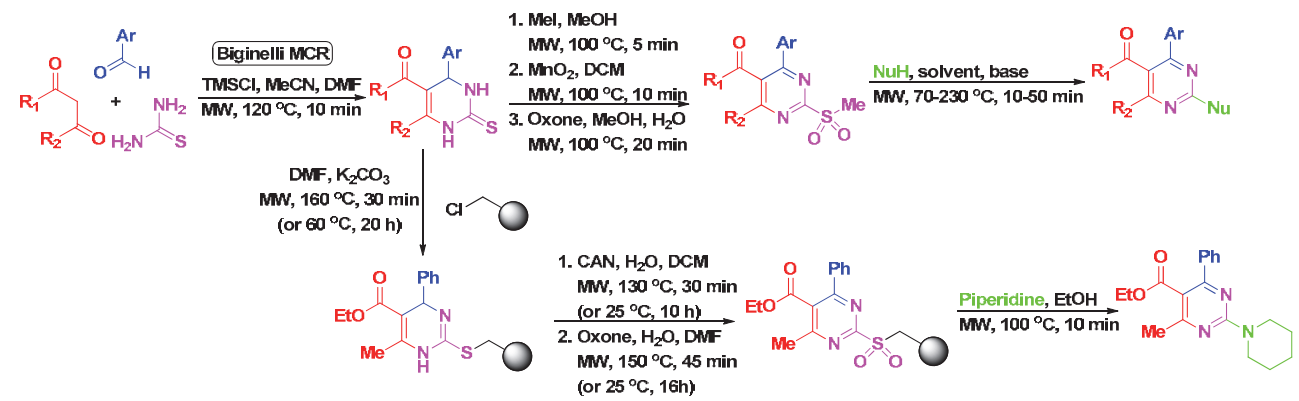

Scheme 14. Initial microwave-assisted Biginelli reaction in solution- and solid-phase synthesis.

\subsubsection{Microwave-assisted synthesis of heterocycles}

Heterocyclic compounds serve both as biomimetics and reactive pharmacophores of numerous drugs. The microwave enhancements have also been utilized in the synthesis of heterocyclic compounds.

Microwave-assisted synthesis allowed rapid preparation of small libraries of imidazolebased privileged heterocyclic structures in high yields and with clean and scalable reactions (Scheme 15) (Fantini, M. et al., 2010).

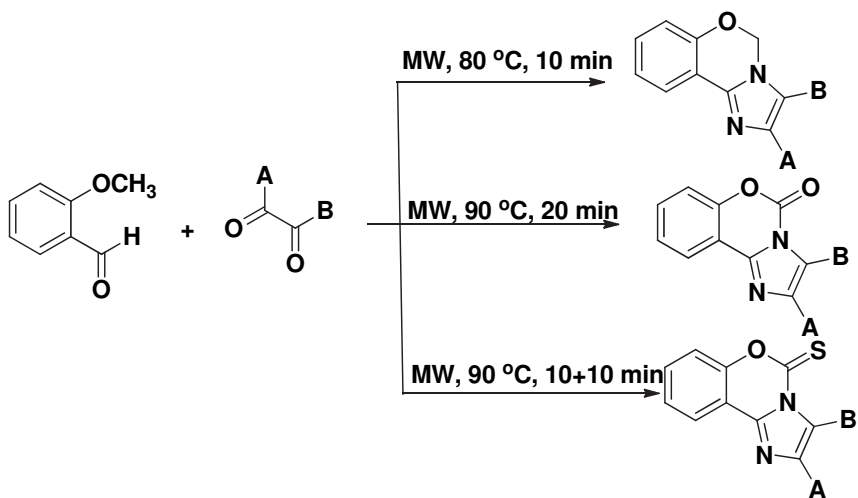

Scheme 15. Microwave synthesis of imidazole-based heterocycles. 
Microwave heating was demonstrated to efficiently generate $N$-substituted 1,3dihydrobenzimidazol-2-ones in good to excellent yields within minutes (Scheme 16). A variety of functional groups can be employed, rendering this method particularly attractive for the efficient preparation of biologically and medicinally interesting molecules ( $\mathrm{Li}, \mathrm{Z}$. et al., 2008a).

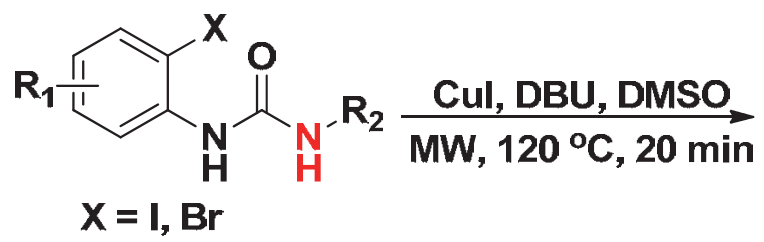<smiles>[R]n1c(=O)[nH]c2cc[R17]cc21</smiles>

Scheme 16. Microwave in the synthesis of heterocycles.

We also developed a microwave-facilitated protocol for fast synthesis of $2 \mathrm{H}-1,4$-benzoxazin3-(4H)-ones via a cascade reaction with a nucleophilic substitution followed by a CuI/DBUcatalyzed coupling cyclization (Scheme 17). This method involved simple reaction conditions, short reaction time and a broad substrate scope in moderate to good yields (Feng, E. et al., 2009).

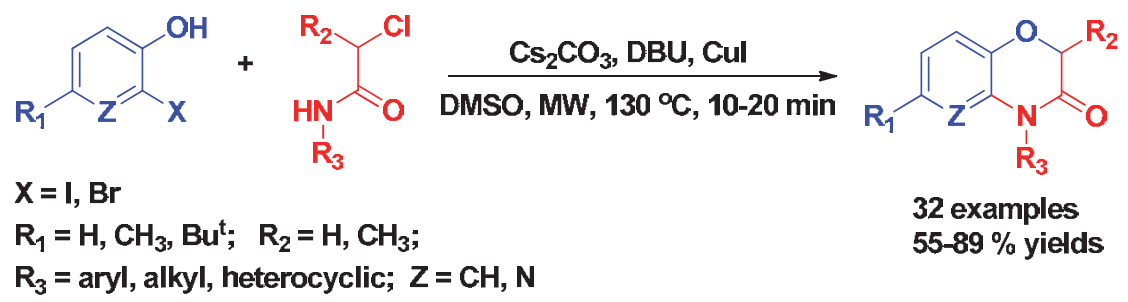

Scheme 17. Microwave in the synthesis of heterocycles.

\subsubsection{Aqueous microwave synthesis}

The development of green synthetic protocols to reduce or eliminate the use and generation of hazardous substances constitutes a major challenge for chemists. In this context, the microwave-assisted organic reaction in water as a green alternative has become an important research area. The water interacts strongly with the microwave irradiation and is rapidly heated to high temperatures, enabling it to act as a less polar pseudo-organic solvent. Also, water is non-flammable, non-explosive and non-toxic, making it safe and ideally green. The combination of microwave chemistry and green chemistry offers great advantages such as dramatically reducing chemical waste and reaction time, rendering it an attractive and sustainable synthetic protocol.

There are many examples of successful application of microwave-assisted green chemistry. An efficient and convenient method was developed for the preparation of 2,4- $(1 \mathrm{H}, 3 \mathrm{H})$ quinazolinediones and 2-thioxoquinazolinones (Scheme 18). Substituted methyl anthranilate reacted with various iso(thio)cyanates in DMSO $/ \mathrm{H}_{2} \mathrm{O}$ without any catalyst or base under microwave irradiation to generate diversity on the 2,4- $(1 \mathrm{H}, 3 \mathrm{H})$-quinazolinediones or 2thioxoquinazolinones. A variety of substrates can participate in the process with good yields 
in $20 \mathrm{~min}$. In particular, after the reaction mixtures were cooled to ambient temperature, a large amount of desired products precipitated and could easily be collected by filtration with higher purities, making this methodology suitable for library synthesis in drug discovery efforts (Li, Z. et al., 2008b).

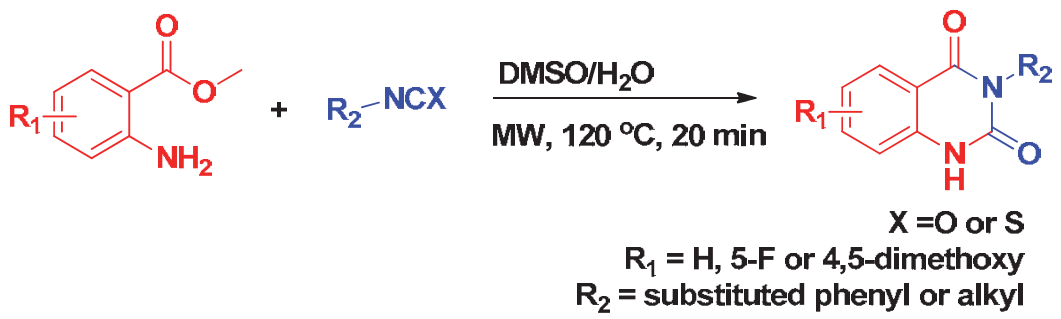

Scheme 18. Microwave-assisted rapid synthesis in $\mathrm{DMSO} / \mathrm{H}_{2} \mathrm{O}$.

Fused tricyclic xanthines have been reported to be potent and selective antagonists of human $\mathrm{A}_{2 \mathrm{~A}}$ adenosine receptors, and have potential activities as anticonvulsants to treat chemically induced seizures. A simple, convenient and green synthetic approach to diverse fused tricyclic xanthines has been developed via gold(I) complex-catalyzed intramolecular hydroamination or silver(I)-catalyzed isomerization-hydroamination of terminal alkynes under microwave irradiation in water (Scheme 19). This reaction is atom economical and has high functional group tolerance (Ye, D. et al., 2009a).

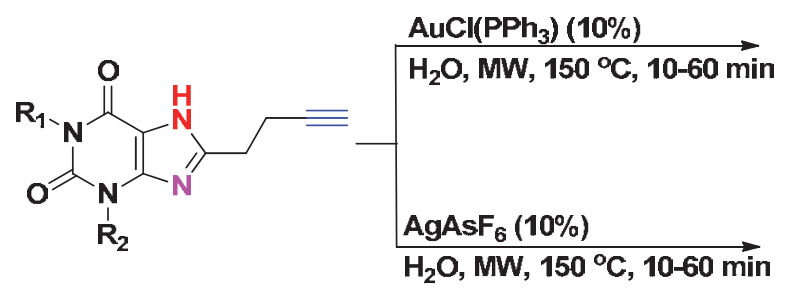<smiles>[R2]n1c(=O)c2c(nc3n2C=CCC3)n([R2])c1=O</smiles><smiles>[R2]n1c(=O)c2nc3n(c2n([R2])c1=O)C=CCC3</smiles>

Scheme 19. Microwave-assisted chemo- and regioselective synthesis of fused tricyclic xanthines in water.

Using $\mathrm{Au}(\mathrm{I})$-catalyzed 5-endo-dig cyclization in water under microwave irradiation, we developed a fast and green route to regioselectively prepare biologically interesting indole1-carboxamides in moderate to high yields (Scheme 20). In comparison, the reaction required 3-48 hours when using traditional oil heating (Ye, D. et al., 2009b).

Under microwave heating, a mild and effective method for the construction of 3hydroxyisoindolin-1-ones via a metal-free tandem transformation using a phase transfer catalyst proceeded in good yields with excellent regioselectivity (Scheme 21). The strategy presents an atom-economical and environmentally friendly transformation, in which one C$\mathrm{O}$ bond and two new $\mathrm{C}-\mathrm{N}$ bonds are formed in water from two simple starting materials (Zhou, Y. et al., 2010). 


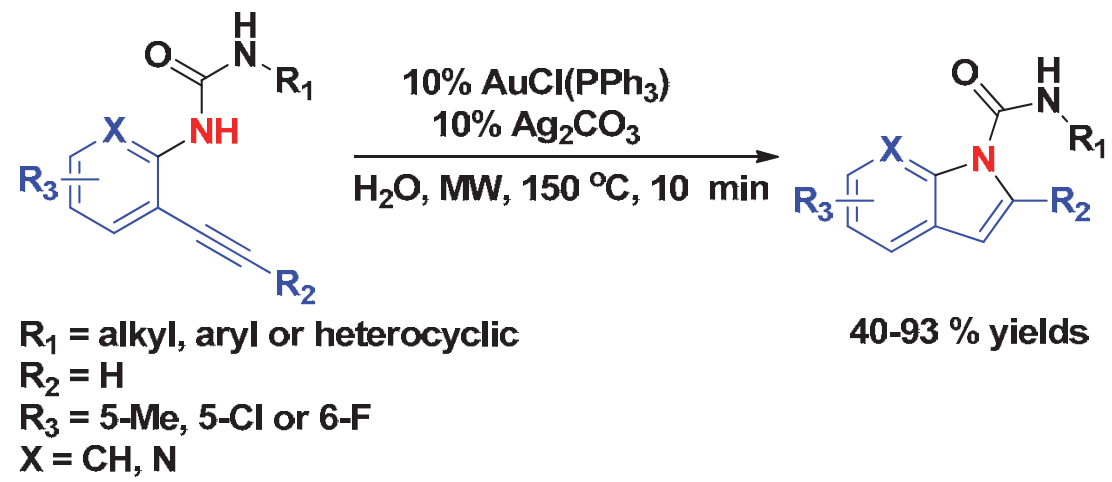

Scheme 20. Microwave-assisted regioselective synthesis of indole-1-carboxamides in water.<smiles>[R]C#Cc1ccc([R3])cc1C(=O)O</smiles><smiles>[R]CN1C(=O)c2cc([R3])ccc2C1(O)CC</smiles>

$70-98 \%$ yields

Scheme 21. Microwave-assisted regioselective synthesis in water.

\section{Microwave synthesis in drug discovery}

In drug discovery and development, rapid synthesis and quick construction of diverse libraries are the main objectives to speed up the process. For its specialty in high speed synthesis, microwave irradiation has now gained wide acceptance as an instrumental technology in the drug discovery programs, including target discovery, library generation for screening, lead generation and optimization endeavours, and process development.

\subsection{Microwave synthesis used alone in drug discovery}

Microwave heating used alone can considerably expedite the synthetic process in drug discovery compared with conventional heating.

\subsubsection{In molecular imaging}

In the preclinical drug discovery, molecular imaging can help validate drug targets in assays of disease and select lead molecules in the chemistry optimization phase. A popular imaging method is positron emission tomography (PET) using radio-labelled pharmaceuticals to non-invasively elucidate biochemical mechanisms in animal and human subjects in vivo. The isotopes employed to label pharmaceuticals in imaging are mainly with short half-lives (carbon ${ }^{11} \mathrm{C}$ for $20 \mathrm{~min}$ and fluorine ${ }^{18} \mathrm{~F}$ for $110 \mathrm{~min}$ ). Therefore, short synthetic routes are crucial to obtain the final product in radio-labelling synthesis. Microwave technology can address the challenges of the rapid labelling of radiopharmaceuticals (Jones, J. R. \& Lu, S., 2006). 


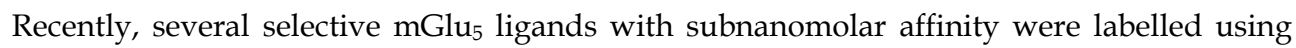
$\left[{ }^{18}\right.$ F]fluoride ion for imaging with PET (Siméon, F. G. et al., 2011). Under microwave irradiation, 2-chlorothiazoles were treated with [18F]fluoride ion in the presence of a potassium fluoride-Kryptofix 2.2.2 (K 2.2.2) complex in DMSO or MeCN, and the respective fluorine-18 labelled compounds were obtained in useful yields (Scheme 22).<smiles>N#Cc1cccc(C#Cc2csc(F)n2)c1</smiles>

Scheme 22. Microwave-assisted rapid labelling for PET.

\subsubsection{Lead generation and optimization}

In the optimization of new HIV-1 protease inhibitors, microwave irradiation was introduced to accelerate a key step in the organic synthesis. With microwave enhancement, target compounds were synthesized using Stille or Suzuki cross-couplings at $120{ }^{\circ} \mathrm{C}$ for $30-50 \mathrm{~min}$, all with retained (S)-configuration at the quaternary carbon. After biological evaluation, up to 56 times more potent compounds exhibiting excellent antiviral activities were obtained.
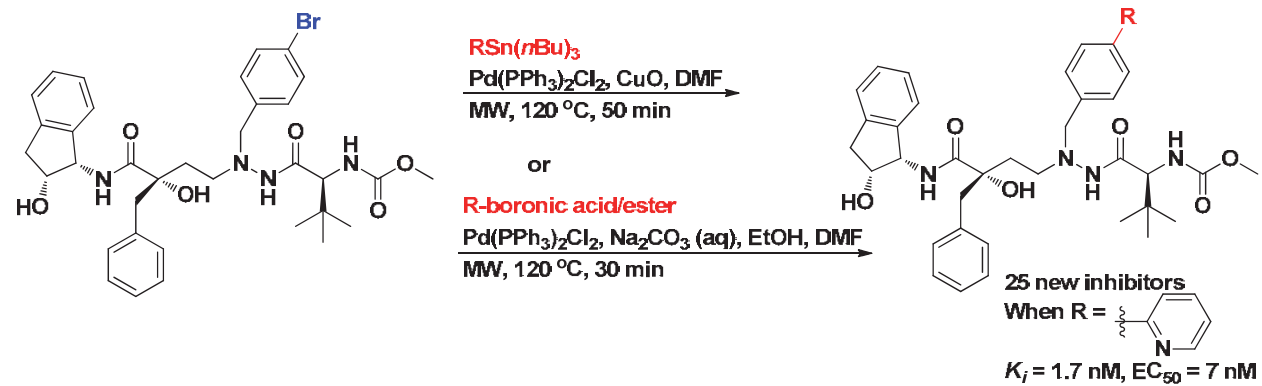

Scheme 23. Microwave-assisted rapid synthesis of target compounds.

\subsection{Microwave synthesis in multidisciplinary approach}

In the post genomic era, there is an ever-increasing demand to synthesize a myriad of substances in a short span of time for biological screening against the vast number of potential drug targets, thus quickly bringing new therapeutics to the market. A variety of strategies and techniques such as click chemistry, green chemistry, multi-component reactions, combinatorial synthesis, parallel synthesis, and automated library production to increase the output of pharmaceutically active chemical entities have been developed. All these techniques and strategies hold their distinguished advantages as well as shortcomings. On the other way, microwave-heating has proven its efficiency in dramatic reduction of reaction time, which is potentially important in drug discovery. Therefore, one of ideal options to accelerate the synthetic processes is to combine microwave chemistry with these techniques in drug discovery. 


\subsubsection{Combined with click chemistry}

After rational docking calculations, a library of 15 compounds was subject to synthesis. Simone et al. took advantage of 1,3-dipolar cycloaddition reaction (click reaction) and subsequent Suzuki cross-coupling reaction to generate the library (Scheme 24). The microwave irradiation technique was introduced in the two steps to provide a faster way to obtain the desired final compounds in satisfactory yields. Biological evaluation of these compounds disclosed three new potential anti-inflammatory drugs (Simone, R. D. et al., 2011).

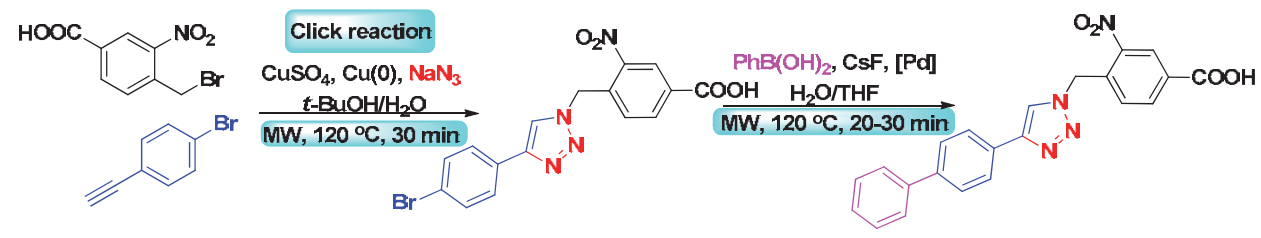

Scheme 24. Microwave synthesis combined with click chemistry.

\subsubsection{Combined with solid-supported combinatorial chemistry}

Combinatorial chemistry has made significantly positive contributions to generate libraries of structurally related compounds. Microwave-enhanced chemistry is ideally suited for combinatorial chemistry in drug discovery to rapid and automated preparation of a large number of compounds for optimization to novel therapeutic agents.

The popular solid-supported combinatorial chemistry simplifies workup and isolation of product which merely involves filtration of the resin and evaporation of the solvent. Its main drawback is the slow kinetics which makes reaction scouting and optimization tedious. Microwave heating has been shown to significantly accelerate the solution-phase combinatorial chemistry.

For example, Murray et al. adapted the microwave irradiation to solid-phase synthesis of $\beta$ peptides on polystyrene (PS) macrobeads. Microwave irradiation allowed rapid synthesis of a high-quality $\beta$-peptide combinatorial library via a split-and-mix approach (Scheme 25). Relative to conventional methods, the microwave approach significantly reduced synthesis time and amounts of reagents (Murray, J. K. et al., 2005).

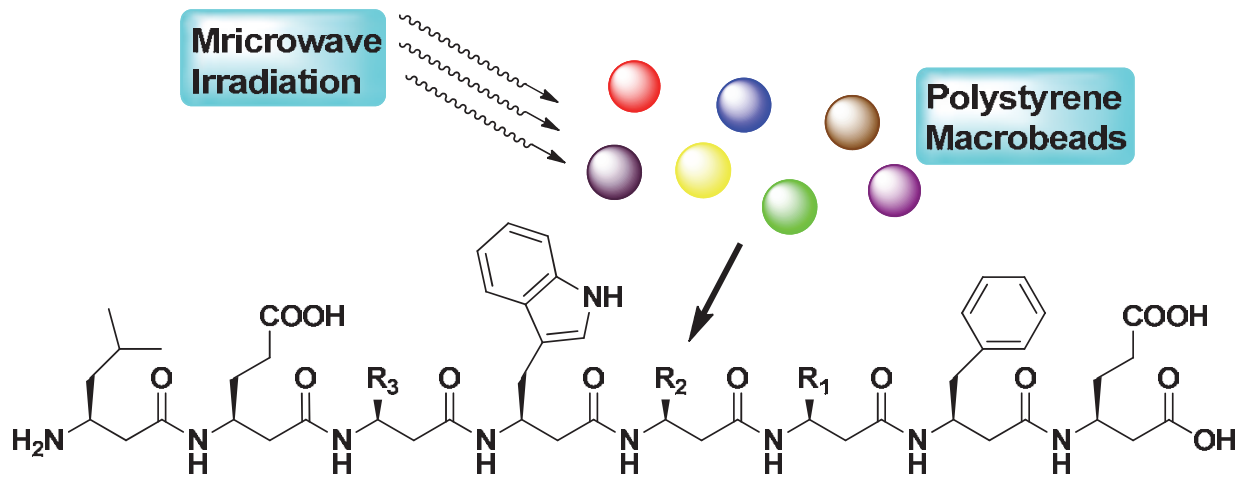

Scheme 25. Microwave synthesis combined with solid-supported combinatorial chemistry. 


\subsubsection{Combined with soluble polymer-supported combinatorial chemistry}

Microwave heating has also been shown to significantly benefit the polymer-supported combinatorial chemistry. For example, the synthesis of indoline substituted nitrobenzene on a polyethylene glycol (PEG) support and its further elaboration to structurally diverse benzene-fused pyrazino/diazepino indoles is recently disclosed (Lin, P. et al., 2011). A reagent based diversification approach coupled with Pictet-Spengler type condensation reactions furnished these fused polycyclic scaffolds. Microwave irradiation was used as a means of rate acceleration for soluble polymer-supported reactions. The efficiency of these fused heterocyclic molecules to inhibit the vascular endothelial growth factor receptor 3 (VEGFR-3) was examined in vitro. A small set of potential drug candidates were identified as novel leads in this therapeutic area (Scheme 26).

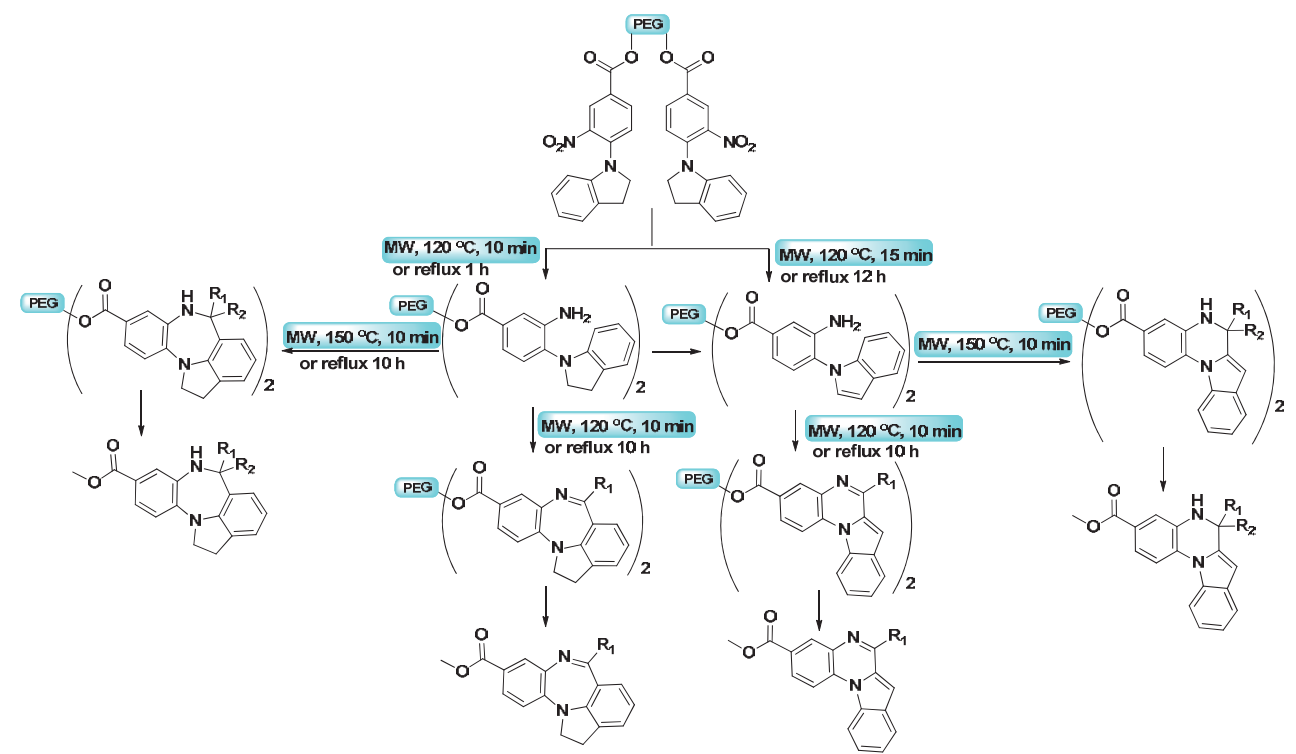

Scheme 26. Microwave irradiation in soluble polymer supported divergent synthesis of heterocyclic library for lead optimization.

\subsubsection{Combined with MCR and parallel synthesis}

In parallel synthesis, a highly reactive intermediate via a series of simple steps is usually synthesized and subsequently subject to a number of different reagents generating a library of compounds.

Zhou et al. demonstrated the efficiency of library synthesis involving a multi-component reaction, microwave heating, and fluorous separation in constructing four diversity points 1,4-benzodiazepine-2,5-diones (BZDs) library via a Ugi/de-Boc/cyclization/Suzuki strategy (Scheme 27). Under microwave heating, cyclohexylisocyanide and methyl 2isocyanoacetate were used as convertible isocyanides for the cyclization reaction to form BZDs. Fluorous benzaldehyde was used as a tagged-component to simplify intermediates and final products purification by simple fluorous solid-phase extraction (Zhou, H. et al., 2010). 


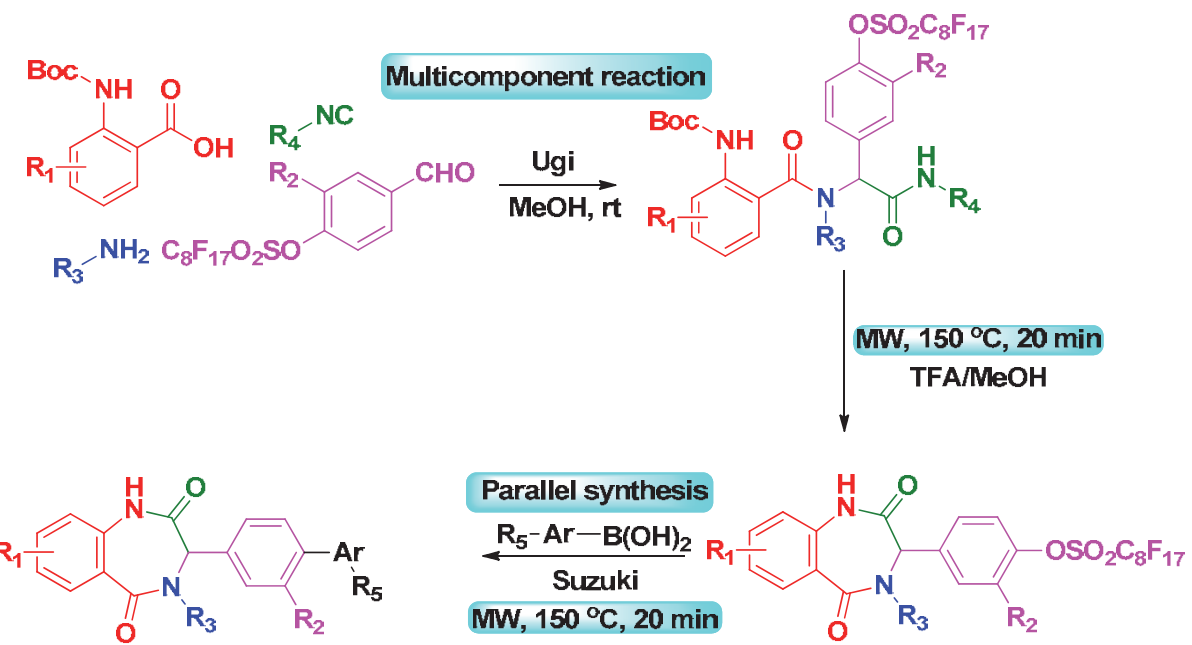

Scheme 27. Microwave-assisted solution-phase fluorous parallel synthesis.

\subsubsection{Combined with MCR and polymer-support combinatorial chemistry}

Hsiao et al. recently reported a new multidisciplinary synthetic approach comprising polymer-support synthesis, microwave-assisted synthesis, and multi-component condensation to facilitate synthesis of triaza-fluorenes library with a set of advantages such as rapid process, simple purification, and structural diversity in one shot (Scheme 28). Microwave irradiation greatly accelerates the rate of all reactions while polymer support facilitates purifications by simple precipitation technique. This strategy dramatically increases the efficiency of the overall multistep synthesis (Hsiao, Y. et al., 2010).

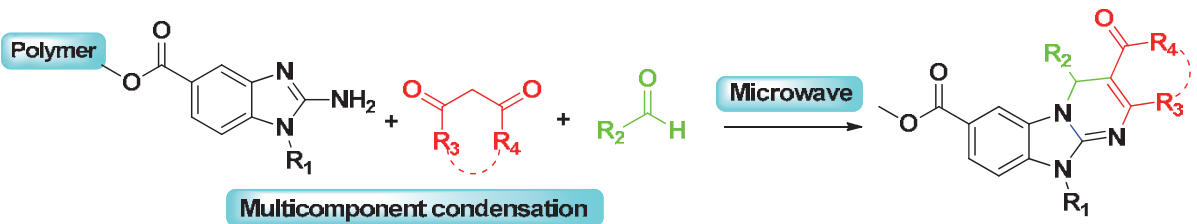

Scheme 28. Multidisciplinary synthetic approach for rapid access of molecules.

\section{Conclusion and outlook}

Microwave heating has gained a wide-spread acceptance both within academia and industry and blossomed into a useful technique for a variety of applications in organic synthesis and drug discovery. In organic chemistry, microwave irradiation allows to obtain rapid, reproducible, and scalable processes to synthesize new molecules in high yields. In drug discovery and development, microwave heating allows the medicinal chemists to get easy and rapid access to a larger number and libraries of novel biologically active compounds.

In spite of the exciting developments, there are still many challenges. The scalability, overall energy efficiency of microwave-heating (Moseley, J. D. \& Kappe, C. O., 2011), and instrument cost remain unresolved. 
Current microwave reactors are able to translate small scale microwave chemistry from milligram or gram scale to multi-kilogram scale using batch or continuous-flow processing. However, many of the benefits of small scale microwave chemistry are lost when the processes performed in larger batch reactors. Also, producing larger quantities of products in tons scale is still a discouraging bottleneck for present microwave reactors. All these challenges need more and dedicated input.

The second disadvantage is equipment cost. Although the cost of microwave reactors have dramatically reduced in recent years, the current price range is still many times higher than that of conventional heating equipment, considerably limiting the uptake of this valuable technology. Continued efforts to develop newer and more readily available microwave reactors as routine equipments of most laboratories are eagerly awaited.

Drug discovery is a challenging and demanding symphony, no one technique alone can whistle it. It is required to take a whole orchestra of strategies and techniques to play it well. In combination there is strength. Microwave chemistry has already been constantly combined with other enabling technologies and strategies such as multi-component reactions, solid-phase organic synthesis, or combinatorial chemistry. The combination of multidisciplinary approaches with microwave heating encourages scientists to initiate new and unexplored areas of complex pharmaceutical systems. To date, microwave irradiation still needs to find promising and tempting combinations with more techniques to satisfy the increased synthetic demands in industry and academia, for example microwave-assisted scale-up in water.

All in all, microwave heating is undoubtedly a bonanza for organic and medicinal chemistry researchers. This enabling technique has changed from the 'last sort' in early days to the 'first choice' nowadays for carrying out synthetic transformations requiring heat. In the future, with lower costs, microwave synthesizers will become an integral part and a standard technology in most synthetic laboratories, and will continually make valuable impact on both organic synthesis and drug discovery.

\section{Acknowledgment}

We gratefully acknowledge financial support from the National Natural Science Foundation of China (Grants 20721003, 81025017 and 20872153) and National S\&T Major Projects (2009ZX09301-001, 2009ZX09501-001 and 2009ZX09501-010).

\section{References}

Baghbanzadeh, M.; Pilger, C. \& Kappe, C. O. (2011). Rapid Nickel-Catalyzed SuzukiMiyaura Cross-Couplings of Aryl Carbamates and Sulfamates Utilizing Microwave Heating. The Journal of Organic Chemistry, Vol. 76, No. 5, (January 2011), pp. 15071510.

Caddick, S. \& Fitzmaurice, R. (2009). Microwave Enhanced Synthesis. Tetrahedron, Vol. 65, No. 17, (April 2009), pp. 3325-3355.

Chen, S.; Huang, H.; Liu,X.; Shen, J.; Jiang, H. \& Liu, H. (2008). Microwave-Assisted Efficient Copper-Promoted N-Arylation of Amines with Arylboronic Acids. Journal of Combinatorial Chemistry, Vol. 10, No. 3, (April 2008), pp. 358-360.

Ding, X.; Ye, D.; Liu, F.; Deng, G.; Liu,G.; Luo, X.; Jiang, H. \& Liu, H. (2009). Efficient Synthesis of $a$-Aryl-/Heteroaryl-Substituted $\beta$-Amino Acids via Ni(II) Complex 
through the Suzuki Coupling Reaction. The Journal of Organic Chemistry, Vol. 74, No. 15, (June 2009), pp. 5656-5659.

Fantini, M.; Zuliani, V.; Spotti, M. A. \& Rivara, M. (2010). Microwave Assisted Efficient Synthesis of Imidazole-Based Privileged Structures. Journal of Combinatorial Chemistry, Vol. 12, No. 1, (November 2010), pp. 181-185.

Feng, E.; Huang, H.; Zhou, Y.; Ye, D.; Jiang, H. \& Liu, H. (2009). Copper(I)-Catalyzed OnePot Synthesis of 2H-1,4-Benzoxazin-3-(4H)-ones from $O$-Halophenols and 2Chloroacetamides. The Journal of Organic Chemistry, Vol. 74, No. 7, (March 2009), pp. 2846-2849.

Gedye, R.; Smith, F.; Westaway, K.; Ali, H.; Baldisera, L.; Laberge, L. \& Rousell, J. (1986). The Use of Microwave Ovens for Rapid Organic Synthesis. Tetrahedron Letters, Vol. 27, No. 3, (January 1986), pp. 279-282.

Giguere, R. J.; Bray, T. L.; Duncan, S. M. \& Majetich, G. (1986). Application of Commercial Microwave Ovens to Organic Synthesis. Tetrahedron Letters, Vol. 27, No. 41, (1986), pp. 4945-4948.

Hao, W.; Jiang, B.; Tu, S.; Cao, X.; Wu, S.; Yan, S.; Zhang, X.; Han, Z. \& Shi, F. (2009). A New Mild Base-catalyzed Mannich Reaction of Hetero-arylamines in Water: Highly Efficient Stereoselective Synthesis of $\beta$-Aminoketones under Microwave Heating. Organic \& Biomolecular Chemistry, Vol. 2009, No. 7, (February 2009), pp. 1410-1414.

Hayes, B. L. (2002). Microwave Synthesis: Chemistry at the Speed of Light, CEM, ISBN 09722229-0-1, USA.

Hsiao, Y.; Yellol, G. S.; Chen, L. \& Sun, C. (2010). Multidisciplinary Synthetic Approach for Rapid Combinatorial Library Synthesis of Triaza-Fluorenes. Journal of Combinatorial Chemistry, Vol. 12, No. 5, (September 2010), pp. 723-732.

Huang, H.; Hong Liu, H.; Jiang, H. \& Chen, K. (2008b). Rapid and Efficient Pd-Catalyzed Sonogashira Coupling of Aryl Chlorides. The Journal of Organic Chemistry, Vol. 73, No. 15, (July 2008), pp. 6037-6040.

Huang, H.; Liu, H.; Chen, K. \& Jiang, H. (2007). Microwave-Assisted Rapid Synthesis of 2,6,9-Substituted Purines. Journal of Combinatorial Chemistry, Vol. 9, No. 2, (February 2007), 197-199.

Huang, H.; Ma, J.; Shi, J.; Meng, L.; Jiang, H., Ding, J. \& Liu, H. (2010). Discovery of Novel Purine Derivatives with Potent and Selective Inhibitory Activity Against c-Src Tyrosine Kinase. Bioorganic \& Medicinal Chemistry, Vol. 18, No. 13, (May 2010), $4615-4624$.

Huang, H.; Yan, X.; Zhu, W.; Liu, H.; Jiang, H. \& Chen, K. (2008a). Efficient CopperPromoted N-Arylations of Aryl Halides with Amines. Journal of Combinatorial Chemistry, Vol. 10, No. 5, (July 2008), 617-619.

Jida, M.; Malaquina, S.; Deprez-Poulain,R.; Laconde, G. \& Deprez, B. (2010). Synthesis of Five- and Six-membered Lactams via Solvent-free Microwave Ugi Reaction. Tetrahedron Letters, Vol. 51, No. 39, (September 2010), pp. 5109-5111.

Jones, J. R. \& Lu, S. (2006). Chapter 18. Microwave-enhanced Radiochemistry, In: Microwaves in Organic Synthesis, 2nd Ed., Loupy, A. pp. 820-859, Wiley-VCH, ISBN 978-3-52731452-2, Weinheim, Germany.

Kappe, C. O. \& Dallinger, D. (2006). The Impact of Microwave Synthesis on Drug Discovery. Nature Reviews Drug Discovery, Vol. 5, (January 2006), pp. 51-63. 
Kappe, C. O. \& Stadler, A. (2005). Microwaves in Organic and Medicinal Chemistry, WileyVCH, ISBN 978-3-527-31210-8, Weinheim, Germany.

Kappe, C. O. (2004). Controlled Microwave Heating in Modern Organic Synthesis. Angewandte Chemie International Edition, Vol 43, No. 46, (November 2004), pp. 62506284.

Kappe, C. O. (2008). Microwave Dielectric Heating in Synthetic Organic Chemistry. Chemical Society Reviews, Vol. 37, No. 6, (April 2008), pp. 1127-1139.

Kappe, C. O.; Dallinger, D. \& Murphree, S.S. (2009). Practical Microwave Synthesis for Organic Chemists: Strategies, Instruments, and Protocols, Wiley-VCH, ISBN 978-3-527-32097-4, Weinheim, Germany.

Khanetskyy, B.; Dallinger, D. \& Kappe, C. O. (2004). Combining Biginelli Multicomponent and Click Chemistry: Generation of 6-(1,2,3-Triazol-1-yl)-Dihydropyrimidone Libraries. Journal of Combinatorial Chemistry, Vol. 6, No. 6, (November 2004), pp. 884-892.

Leadbeater, N. E. (2010). Microwave Heating as a Tool for Sustainable Chemistry, CRC Press, ISBN 978-1-4398-1270-9, Boca Raton, USA.

Li, Z.; Huang, H.; Sun, H.; Jiang, H. \& Liu, H. (2008b). Microwave-Assisted Efficient and Convenient Synthesis of 2,4- $(1 H, 3 H)$-Quinazolinediones and 2-Thioxoquinazolines. Journal of Combinatorial Chemistry, Vol. 10, No. 3, (April 2008), pp. 484-486.

Li, Z.; Sun, H.; Jiang, H. \& Liu, H. (2008a). Copper-Catalyzed Intramolecular Cyclization to N-Substituted 1,3-Dihydrobenzimidazol-2-ones. Organic Letters, Vol. 10, No. 15, (July 2008), pp. 3263-3266.

Lin, P.; Salunke, D. B.; Chen L. \& Sun, C. (2011). Soluble Polymer Supported Divergent Synthesis of Tetracyclic Benzene-fused Pyrazino/diazepino indoles: an Advanced Synthetic Approach to Bioactive Scaffolds. Organic \& Biomolecular Chemistry, Vol. 9, No. 8, (2011), pp. 2925-2937.

Lindh, J.; Enquist,P.; Pilotti, Å.; Nilsson, P. \& Larhed, M. (2007). Efficient Palladium(II) Catalysis under Air. Base-Free Oxidative Heck Reactions at Room Temperature or with Microwave Heating. The Journal of Organic Chemistry, Vol. 72, No. 21, (September 2007), pp. 7957-7962.

Loupy, A. (2006). Microwaves in Organic Synthesis, 2nd Ed., Wiley-VCH, ISBN 978-3-52731452-2, Weinheim, Germany.

Matloobi, M. \& Kappe, C. O. (2007). Microwave-Assisted Solution- and Solid-Phase Synthesis of 2-Amino-4-arylpyrimidine Derivatives. Journal of Combinatorial Chemistry, Vol. 9, No. 2, (March 2007), pp. 275-284.

Mavandadi, F. \& Lidström, P. (2004) Microwave-Assisted Chemistry in Drug Discovery. Current Topics in Medicinal Chemistry, Vol. 4, No. 7, (2004), pp. 773-792.

Mavandadi, F. \& Pilotti, ̊. (2006). The Impact of Microwave-assisted Organic Synthesis in Drug Discovery. Drug Discovery Today, Vol. 11, No. 3-4, (February 2006), pp. 165174.

Mazuela, J.; Pàmies, O. \& Diéguez, M. (2010). Biaryl Phosphite-Oxazoline Ligands from the Chiral Pool: Highly Efficient Modular Ligands for the Asymmetric Pd-Catalyzed Heck Reaction. Chemistry - A European Journal, Vol. 16, No. 11, (March 2010), pp. 3434-3440. 
Miao, G.; Ye, P.; Yu, L. \& Baldino, C. M. (2005). Microwave-Promoted Suzuki Reactions of Aryl Chlorides in Aqueous Media. The Journal of Organic Chemistry, Vol. 70, No. 6, (February 2005), pp. 2332-2334.

Moseley, J. D. \& Kappe, C. O. (2011). A Critical Assessment of the Greenness and Energy Efficiency of Microwave-assisted Organic Synthesis. Green Chemistry, Vol. 13, No. 4, (April 2011), pp. 794-806.

Murray, J. K.; Farooqi, B.; Sadowsky, J. D.; Scalf, M.; Freund, W. A.; Smith, L. M.; Chen, J. \& Gellman, S. H. (2005). Efficient Synthesis of a $\beta$-Peptide Combinatorial Library with Microwave Irradiation. Journal of the American Chemical Society, Vol. 127, No. 38, (September 2005), pp. 13271-13280.

Nun, P.; Martinez, J. \& Lamaty, F. (2009). Solvent-Free Microwave-Assisted Suzuki-Miyaura Coupling Catalyzed by PEPPSI-iPr. Synlett, No. 11, (December 2009), pp. 17611764 .

Pisani, L.; Prokopcová, H.; Kremsner, J. M. \& Kappe, C. O. (2007). 5-Aroyl-3,4dihydropyrimidin-2-one Library Generation via Automated Sequential and Parallel Microwave-assisted Synthesis Techniques. Journal of Combinatorial Chemistry, Vol. 9, No. 3, (May 2007), pp. 415-421.

Polshettiwar, V. (2010). Aqueous Microwave Assisted Chemistry: Synthesis and Catalysis, The Royal Society of Chemistry, ISBN 978-1-84973-038-9, Cambridge, UK.

Rodríguez B. \& Bolm, C. (2006). Thermal Effects in the Organocatalytic Asymmetric Mannich Reaction. The Journal of Organic Chemistry, Vol. 71, No. 7, (February 2006), pp. 2888-2891.

Siméon, F. G.; Wendahl, M. T. \& Pike, V. W. (2011). Syntheses of 2-Amino and 2Halothiazole Derivatives as High-Affinity Metabotropic Glutamate Receptor Subtype 5 Ligands and Potential Radioligands for in Vivo Imaging. Journal of Medicinal Chemistry, Vol. 54, No. 3, (January 2011), pp. 901-908.

Simone, R. D.; Chini, M. G.; Bruno, I.; Riccio, R.; Mueller, D.; Werz, O. \& Bifulco, G. (2011). Structure-Based Discovery of Inhibitors of Microsomal Prostaglandin $\mathrm{E}_{2}$ Synthase1, 5-Lipoxygenase and 5-Lipoxygenase-Activating Protein: Promising Hits for the Development of New Anti-inflammatory Agents. Journal of Medicinal Chemistry, Vol. 54, No. 6, (February 2011), pp. 1565-1575.

Tierney, J. P. \& Lidström, P. (2005). Microwave Assisted Organic Synthesis, Blackwell, ISBN 14051-1560-2, USA and Canada.

Wathey, B.; Tierney, J.; Lidström, P. \& Westman, J. (2002). The Impact of Microwave-assisted Organic Chemistry on Drug Discovery. Drug Discovery Today, Vol. 7, No. 6, (March 2002), pp. 373-380.

Ye, D.; Wang, J.; Zhang, X.; Zhou, Y.; Ding, X.; Feng, E.; Sun, H.; Liu, G.; Jiang, H. \& Liu, H. (2009b). Gold-catalyzed Intramolecular Hydroamination of Terminal Alkynes in Aqueous Media: Efficient and Regioselective Synthesis of Indole-1-carboxamides. Green Chemistry, Vol. 11, No. 8, (May 2009), pp. 1201-1208.

Ye, D.; Zhang, X.; Zhou, Y.; Zhang, D.; Zhang, L.; Wang, H.; Jiang, H. \& Liu, H. (2009a). Gold- and Silver-Catalyzed Intramolecular Hydroamination of Terminal Alkynes: Water-Triggered Chemo- and Regioselective Synthesis of Fused Tricyclic Xanthines. Advanced Synthesis \& Catalysis, Vol. 351, Iss. 17, (November 2009), pp. 2770-2778. 
Zhou, H.; Zhang, W. \& Yan, B. (2010). Use of Cyclohexylisocyanide and Methyl 2Isocyanoacetate as Convertible Isocyanides for Microwave-Assisted Fluorous Synthesis of 1,4-Benzodiazepine-2,5-dione Library. Journal of Combinatorial Chemistry, Vol. 12, No. 1, (November 2009), pp. 206-214.

Zhou, Y.; Zhai, Y.; Li, J.; Ye, D.; Jiang, H. \& Liu, H. (2010). Metal-free Tandem Reaction in Water: An Efficient and Regioselective Synthesis of 3-Hydroxyisoindolin-1-ones. Green Chemistry, Vol. 12, No. 8, (July 2010), pp. 1397-1404. 


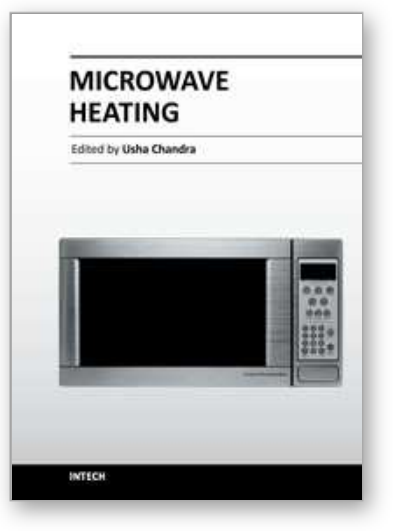

\author{
Microwave Heating \\ Edited by Dr. Usha Chandra
}

ISBN 978-953-307-573-0

Hard cover, 370 pages

Publisher InTech

Published online 27, July, 2011

Published in print edition July, 2011

The Microwave heating has not only revolutionized the food industry but also has extended its wings widely towards its multidimensional applications. Thus it has opened new vistas of potential research in science and technology. The book is compiled into Seventeen Chapters highlighting different aspects varying from epistemological discussion to applicability of conceptual constructs. The inclusion of discussion on the avenues in the field of Chemistry, Health \& Environment, Medical Sciences and Technology makes it an exquisite work for the aspirant Researchers. As the text book for the beginners, it is designed fundamentally to be a reference monograph to the experts providing a passage for future research. The plethora of literatures are available on Microwave Applications but they seldom direct their readers to concentrate on the key aspects behind the success in microwave applications in different fields. Here is the attempt to fill up the gap with this book.

\title{
How to reference
}

In order to correctly reference this scholarly work, feel free to copy and paste the following:

Hong Liu and Lei Zhang (2011). Microwave dielectric heating in modern organic synthesis and drug discovery, Microwave Heating, Dr. Usha Chandra (Ed.), ISBN: 978-953-307-573-0, InTech, Available from: http://www.intechopen.com/books/microwave-heating/microwave-dielectric-heating-in-modern-organicsynthesis-and-drug-discovery

\section{INTECH}

open science | open minds

\author{
InTech Europe \\ University Campus STeP Ri \\ Slavka Krautzeka 83/A \\ 51000 Rijeka, Croatia \\ Phone: +385 (51) 770447 \\ Fax: +385 (51) 686166 \\ www.intechopen.com
}

\author{
InTech China \\ Unit 405, Office Block, Hotel Equatorial Shanghai \\ No.65, Yan An Road (West), Shanghai, 200040, China \\ 中国上海市延安西路65号上海国际贵都大饭店办公楼 405 单元 \\ Phone: +86-21-62489820 \\ Fax: +86-21-62489821
}


(C) 2011 The Author(s). Licensee IntechOpen. This chapter is distributed under the terms of the Creative Commons Attribution-NonCommercialShareAlike-3.0 License, which permits use, distribution and reproduction for non-commercial purposes, provided the original is properly cited and derivative works building on this content are distributed under the same license. 